\title{
Clonal antigen receptor gene PCR products outside the expected size range
}

\author{
Paul G. Rothberg • Anton W. Langerak • \\ Brenda Verhaaf • Jacques J. M. van Dongen • \\ W. Richard Burack • Mahlon D. Johnson • \\ Donald Slate • Todd S. Laughlin • Karen Payne • \\ Luis Figueiredo - Betty N. Bandoh • Qingguo Yan • \\ Chris M Bacon • Penny Wright • Anthony Bench • \\ Ming-Qing Du $\cdot$ Hongxiang Liu
}

Received: 16 August 2011 /Accepted: 26 December 2011 /Published online: 3 February 2012

(C) Springer-Verlag 2012

\begin{abstract}
Polymerase chain reaction (PCR) of the antigen receptor genes has clinical utility in establishing clonality in lymphoproliferations, which is an important correlate of lymphoid neoplasia. The most frequently used procedures
\end{abstract}

P. G. Rothberg $(\bowtie) \cdot$ W. R. Burack $\cdot$ M. D. Johnson •

T. S. Laughlin

Department of Pathology and Laboratory Medicine, University of Rochester Medical Center,

Rochester, NY 14642, USA

e-mail: paul_rothberg@urmc.rochester.edu

A. W. Langerak $\cdot$ B. Verhaaf $\cdot$ J. J. M. van Dongen

Department of Immunology, Erasmus MC,

University Medical Center,

Rotterdam, The Netherlands

D. Slate

Mercy Hospital,

Buffalo, NY, USA

K. Payne $\cdot$ P. Wright $\cdot$ H. Liu

Department of Histopathology, Addenbrooke's Hospital, Cambridge University Hospitals NHS Foundation Trust,

Cambridge, UK

L. Figueiredo $\cdot$ B. N. Bandoh $\cdot$ A. Bench $\cdot$ H. Liu

Molecular Malignancy Laboratory, Addenbrooke's Hospital,

Cambridge University Hospitals NHS Foundation Trust,

Cambridge, UK

Q. Yan • M.-Q. Du

Department of Pathology, University of Cambridge,

Cambridge, UK

C. M. Bacon

Northern Institute for Cancer Research, Newcastle University,

Newcastle upon Tyne, UK for this purpose were developed by the BIOMED-2 consortium. One of the criteria for establishing monoclonality using PCR of the antigen receptor genes is the finding of an abundant amplicon within a size range determined by the positions of the PCR primers and the known variability in size inherent in the recombination events that assemble a functional antigen receptor gene. However, several cases have been reported in which an amplicon outside this size range has been shown to be a valid indicator of clonality after DNA sequence analysis. In this paper, we will report and discuss several additional cases in which an amplicon outside the accepted size range was consistent with a monoclonal lymphoproliferation. We conclude that oversized and undersized amplicons may indeed represent evidence for a monoclonal lymphoproliferation, but that this interpretation should preferably be confirmed by sequence analysis to avoid a false-positive result.

Keywords Lymphoma $\cdot$ BIOMED-2 Antigen receptor PCR $\cdot$ Clonality $\cdot$ Immunoglobulin genes $\cdot$ T-cell receptor genes

\section{Introduction}

Rearrangement of the immunoglobulin (IG) and T-cell receptor $(T C R)$ genes, as detected using the polymerase chain reaction (PCR), has proven to be a useful marker of clonality to aid in the diagnosis of lymphoid malignancies. When the antigen receptor genes are in a germline configuration, the variable $(\mathrm{V})$ and joining $(\mathrm{J})$ genes are too far apart to form a PCR product (amplicon) under the conditions of 
the assay. However, after normal V(D)J gene rearrangement, they are much closer and a DNA fragment is amplified. Due to the size and sequence variability of the amplicons from a polyclonal lymphoproliferation, they can be distinguished from the uniform size and sequence of the amplicon(s) derived from a monoclonal proliferation. The size of the amplicon produced by PCR of the antigen receptor genes is variable for each set of primers because of variations in trimming and $\mathrm{N}$-addition during the process of $\mathrm{V}(\mathrm{D}) \mathrm{J}$ recombination $[1,2]$.

The BIOMED-2 program has contributed toward the optimization and standardization of this methodology, particularly in the area of primer design [3]. Many laboratories routinely use the BIOMED-2 primer sets to confirm monoclonality in suspected lymphoproliferations [4-15]. One of the considerations for establishing a monoclonal result is for the size of the amplicon to be within acceptable limits based on the positions of the primers and known patterns of trimming and $\mathrm{N}$-addition during $\mathrm{V}(\mathrm{D}) \mathrm{J}$ recombination. The purpose of this size limit is to avoid false-positives due to amplification of an unrelated sequence that does not reflect clonality. In previous work, we and others have shown that an amplicon from $I G H$ PCR that was smaller than the acceptable limits was the product of a normal recombination event followed by a deletion, but still supported a finding of clonality $[16,17]$. In this paper, we show several additional cases in which amplicons outside of the expected size range (both larger and smaller) from the IG and TCR genes support a finding of clonality.

\section{Materials and methods}

\section{DNA isolation}

DNA was isolated from formalin-fixed paraffin-embedded (FFPE) tissues, blood, or bone marrow using the QIAamp system (Qiagen Inc., Valencia, CA, USA) or the GenElute system (Sigma Genosys. Haverhill, UK). The concentration of DNA was estimated by specrophotometry using the Nanodrop ND-1000 spectrophotometer (Wilmington, DE, USA).

\section{Clonality analysis}

The quality of DNA extracted from FFPE tissues was assessed using the BIOMED-2 specimen control reaction [3]. Clonality analysis was carried out using the BIOMED2 PCR mastermixes purchased from Invivoscribe Inc. (San Diego, CA, USA). After PCR, the products were heteroduplex-treated (denaturation at $95^{\circ} \mathrm{C}$ for $5 \mathrm{~min}$ followed by rapid renaturation at $4^{\circ} \mathrm{C}$ for $1-2 \mathrm{~h}$ ), and then resolved by polyacrylamide gel electrophoresis (PAGE), or subjected to Gene Scanning as previously described $[3,10]$.

\section{Sequence analysis}

When gel purification was needed, the PCR products were extracted from the polyacrylamide gels using the QIAquick Gel Extraction Kit (Qiagen, West Sussex, UK). When gel purification was not used, the PCR products were treated using ExoSap (Amersham Biosciences, Pittsburgh, PA, USA). Sequencing reactions were done using the PCR primers as sequencing primers, and the dye-labeled products were separated on the ABI 377 or ABI 3100 Prism DNA sequencer (Applied Biosystems, Inc. Foster City, CA, USA). The sequences were aligned to the germline sequences and studied with the use of the IMGT (http://www.imgt. org/) and GenBank databases (http://www.ncbi.nlm.nih.gov/ igblast/showGermline.cgi). The complete sequences for cases 1-4 and case 6 are available from GenBank, accession numbers JN662464, JN678807, JN678808, JN678809, and JQ267758, respectively.

\section{Results}

Case 1: Oversized PCR product from a rearranged IGH gene

A FFPE biopsy from the left para-orbital region of the brain was received for pathological evaluation. The sections showed considerable crush artifact, but revealed a lymphoplasmacytic and monocyte/histiocytic infiltrate without an overtly malignant population (Fig. 1a). This impression in the setting of poorly preserved morphology prompted the
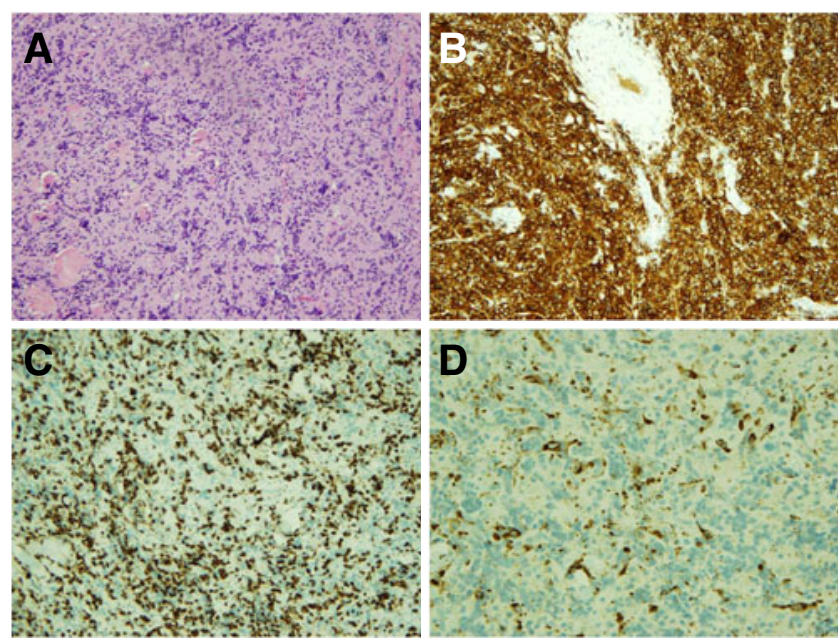

Fig. 1 Histology and immunohistochemical analysis of the brain biopsy in case 1 . a H\&E stained low power photomicrograph. b Immunostain for CD79a. $\mathbf{c}$ Immunostain for CD3. d Immunostain for CD68. All figures, $\times 200$ 
decision to submit tissue for PCR-based clonality assays, in addition to immunohistochemical studies. Deeper levels showed discohesive cells with large nuclei and prominent nucleoli. Membranous CD20 and CD79a (Fig. 1b) staining was prominent. Scattered small mature appearing lymphocytes expressed CD3 (Fig. 1c). Immunohistochemical stains for light chains suggested a predominance of kappa expression in the large cells but nonspecific staining was high; plasma cells showed mixed expression of kappa and lambda light chains. Only a fraction of the cellularity appeared to be monocyte/macrophages based on CD68 expression (Fig. 1d). Alk-1, S100, CD1a, CD56, GFAP, synaptophysin, Neu-N, EMA, and CAM 5.2 were negative. The lesional cells showed brisk Ki-67 labeling and occasional nuclear p53 immunoreactivity. No fungi or encysted forms were found; GMS and AFB were negative.

DNA purified from the specimen was studied for evidence of clonality using PCR to detect rearrangement of the $I G H$ gene. A finding of a monoclonal B-lymphocyte proliferation would support a diagnosis of lymphoma. A homoduplex of approximately $500 \mathrm{bp}$ was obtained from the $\mathrm{V}_{\mathrm{H}}$ FR3 and $\mathrm{J}_{\mathrm{H}}$ primers (BIOMED-2 IGH tube C), which is much larger than the usually acceptable size limits of 100 $170 \mathrm{bps}$ for this primer set (Fig. 2a). PCR using the BIOMED-2 $V_{\mathrm{H}}$ FR $2 / \mathrm{J}_{\mathrm{H}}$ primer set (tube $\mathrm{B}$ ) did not give interpretable results (data not shown). We sequenced the amplicon from the FR3/ $\mathrm{J}_{\mathrm{H}}$ PCR using the downstream consensus $\mathrm{J}_{\mathrm{H}}$ primer as the sequencing primer. The sequence was completed using an internal sequencing primer determined using the results from the first round of sequencing. The sequence is described with the diagram in Fig. 2b. The sequence was consistent with a 549-bp amplicon that used a $\mathrm{V}_{\mathrm{H}} 4$ gene, $\mathrm{D}_{\mathrm{H}} 3-9$ gene, and $\mathrm{J}_{\mathrm{H}} 4$ gene. However, there were three mismatches between the BIOMED-2 $\mathrm{J}_{\mathrm{H}}$ primer and the primer target in the $\mathrm{J}_{\mathrm{H}} 4$ gene, including a mismatch at the $3^{\prime}$ terminal base (Fig. 2b, lower panel). This sequence was followed by the intergenic sequence between $\mathrm{J}_{\mathrm{H}} 4$ and $\mathrm{J}_{\mathrm{H}} 5$. Thus, the sequence revealed that the reason for the enlarged amplicon is that the $\mathrm{J}_{\mathrm{H}}$ PCR primer did not prime on the $\mathrm{J}_{\mathrm{H}} 4$ gene that was used for recombination, due to the mismatches shown in Fig. 2b, but rather on the downstream $\mathrm{J}_{\mathrm{H}} 5$ gene. The sequence of the region between the primer binding sites in $\mathrm{J}_{\mathrm{H}} 4$ and $\mathrm{J}_{\mathrm{H}} 5$ in the amplicon from the FR3/ $\mathrm{J}_{\mathrm{H}}$ PCR and the nearest match from a BLAST search [18] was approximately $83 \%$ (63 mismatches out of 379 nucleotides), which is consistent with extensive somatic hypermutation. Thus, the sequence divergence between the amplicon and the $\mathrm{J}_{\mathrm{H}}$ primer is most likely due to somatic hypermutation rather than a preexisting polymorphism, although the latter cannot be ruled out. One of the divergent nucleotides between the $\mathrm{J}_{\mathrm{H}}$ primer and the amplicon, the antepenultimate $5^{\prime} \mathrm{T}$ in the primer, was part of the original design of the consensus $\mathrm{J}_{\mathrm{H}}$ primer [3].

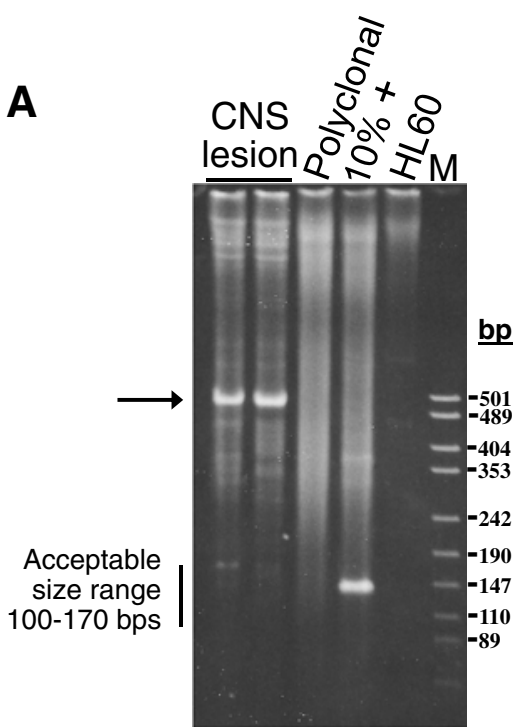

B

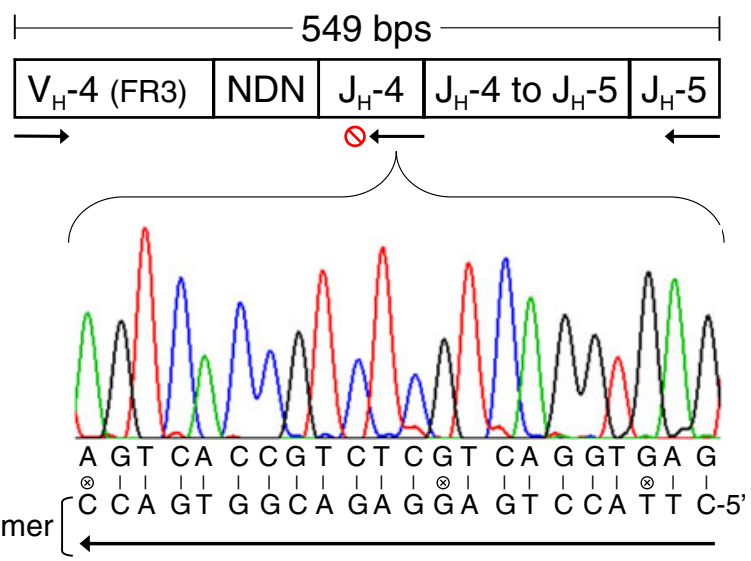

Fig. 2 PCR and sequence analysis of the oversized IGH gene rearrangement from case 1 . a Photograph of a stained heteroduplex polyacrylamide gel. The upstream primers target the $I G H \mathrm{~V}$ gene FR3 regions, and the downstream primer is a consensus $\mathrm{J}_{\mathrm{H}}$ gene primer. The patient specimen (CNS lesion) was analyzed in duplicate. The lanes with controls are labeled in the figure, and are left to right, polyclonal (normal lymphocyte), $10 \%+$ (mixture of $10 \%$ monoclonal $+90 \%$ polyclonal), and HL60 (germline). The lane labeled $M$ contains size markers, with the size of each marker in base pairs $(b p)$ indicated. The abundant approximately 500-bp amplicon is indicated with an arrow. The region of the gel with the acceptable size range of $100-170 \mathrm{bps}$ is indicated by a vertical line to left of the gel photograph. b The top panel is a diagram showing the regions in the amplicon defined by nucleotide sequence analysis. The regions are not drawn to scale. The positions of the upstream and downstream primers are indicated by arrows below the left and right end of the diagram. The arrow under the $\mathrm{J}_{\mathrm{H}} 4$ gene shows the position of the primer that failed to prime efficiently because of sequence differences with the template. The complete sequence of the amplicon between the primers consisted of $47 \mathrm{bps}$ from the $\mathrm{V}_{\mathrm{H}}$ gene (including $25 \mathrm{bp}$ upstream primer), $17 \mathrm{~N}$ nucleotides upstream, and 30 downstream of the $6 \mathrm{bp} \mathrm{D}_{\mathrm{H}}$ gene, 48 bp of $\mathrm{J}_{\mathrm{H}} 4$ sequence, 346 bp between $\mathrm{J}_{\mathrm{H}} 4$ and $\mathrm{J}_{\mathrm{H}} 5$, and $55 \mathrm{bp}$ of $\mathrm{J}_{\mathrm{H}} 5$ (including $22 \mathrm{bp}$ from the downstream primer). The bottom panel shows the sequence trace of the primer binding site in $\mathrm{J}_{\mathrm{H}} 4$. Below this is the sequence interpretation written $5^{\prime} \rightarrow 3^{\prime}$, compared with the sequence of the BIOMED-2 consensus $\mathrm{J}_{\mathrm{H}}$ primer written $3^{\prime} \rightarrow 5^{\prime}$. The complementary nucleotides are connected by vertical lines, and the mismatches indicated by $\mathrm{a} \otimes$ 
The results of the IGH PCR were consistent with a population of monoclonal B-lymphocytes that had experienced somatic hypermutation. The molecular evidence together with the morphological and immunophenotypic evaluation supported a diagnosis of B-cell lymphoma, large cell type.

Case 2: Undersized PCR products from a rearranged IGH gene

A cervical lymph node biopsy from a 60 -year-old male was submitted to the hematopathology service for a second opinion. The lymph node showed a preserved architecture and reactive features, but there were several large follicles with markedly expanded germinal centers. The large follicles had attenuated mantle zones, and the germinal centers contained a uniform population of small centroblastic cells with slightly irregular nuclei and lacked polarity. The centroblasts were $\mathrm{CD} 20+, \mathrm{CD} 10+, \mathrm{BCL} 6+, \mathrm{IgM}+, \mathrm{IgD}+$ (weak), BCL2-, and showed high nuclear staining with MIB-1. CD21 staining showed an attenuated follicular dendritic cell meshwork underlying these germinal centers. The morphological and immunohistochemical findings were suspicious for partial involvement of the lymph node by follicular lymphoma. Consequently, molecular evidence of clonality was sought to assist the diagnosis.

DNA was extracted from the FFPE lymph node specimen and its quality was adequate for clonality analysis as the 400bp control gene PCR product was successfully amplified. PCR for $V_{K}-J_{K}$ and $V_{K}-K_{d e}$ rearrangements both showed a clonal band pattern with a polyclonal background (data not shown). PCR for $\mathrm{V}_{\mathrm{H}}$ FR1- $\mathrm{J}_{\mathrm{H}}$ and $\mathrm{V}_{\mathrm{H}} \mathrm{FR} 2-\mathrm{J}_{\mathrm{H}}$ both also showed a distinct homoduplex band with a polyclonal background. However, the band size was $\sim 50$ bp below the lower end of the expected size range for each respective PCR (Fig. 3, top panels). PCR for $\mathrm{V}_{\mathrm{H}} \mathrm{FR} 3-\mathrm{J}_{\mathrm{H}}, \mathrm{D}_{\mathrm{H}}-\mathrm{J}_{\mathrm{H}}$, and $\mathrm{V}_{\lambda}-\mathrm{J}_{\lambda}$ showed polyclonal results. Sequencing of the $\mathrm{V}_{\mathrm{H}}$ FR2- $\mathrm{J}_{\mathrm{H}}$ PCR product showed a 197-bp nucleotide sequence that aligned to the germline $\mathrm{V}_{\mathrm{H}} 4-59 * 02, \mathrm{D}_{\mathrm{H}} 3-10 * 01$, and $\mathrm{J}_{\mathrm{H}} 4 * 03$ genes, but also had an 81-bp deletion within the $\mathrm{V}$ gene from CDR2 through the 5'-part of FR3 (Fig. 3, bottom panel). The undersized PCR product was therefore amplified from a rearranged $I G H$ gene. As the deletion occurred downstream of the $\mathrm{V}_{\mathrm{H}}$ FR1 and FR2 primer binding sites, both $\mathrm{V}_{\mathrm{H}} \mathrm{FR} 1-\mathrm{J}_{\mathrm{H}}$ and $\mathrm{V}_{\mathrm{H}}$ FR2- $\mathrm{J}_{\mathrm{H}}$ PCR products were undersized by the same length. The rearranged gene lacked an open reading frame and harbored 12 somatic point mutations including three mutations at the $V_{H}$ FR3 primer binding site, which was likely the cause for failure of $\mathrm{V}_{\mathrm{H}}$ FR3- $\mathrm{J}_{\mathrm{H}}$ PCR.

The results of $\mathrm{V}_{\mathrm{H}}-\mathrm{J}_{\mathrm{H}}$ PCR were consistent with those of $\mathrm{V}_{\mathrm{K}}-\mathrm{J}_{\mathrm{K}}$ and $\mathrm{V}_{\mathrm{K}}-\mathrm{K}_{\mathrm{de}} \mathrm{PCR}$, suggesting that a clonal B-cell population was present within a reactive background in the specimen. The molecular evidence for clonality, together with the atypical morphological and immunophenotypic features described above, supported a diagnosis of partial involvement by follicular lymphoma, WHO grade $3 \mathrm{~b}$.

\section{Case 3: Oversized PCR products from a rearranged IGK} gene

A 22-year-old male with a 4-year history of renal transplantation for reflux nephropathy, presented with abdominal pain and diarrhea. Radiological examination showed a mass in the cecum and a biopsy was taken. The cecal biopsy consisted of small fragments of ulcerated granulation tissue showing an inflammatory background and areas with predominantly large pleomorphic lymphoid cells. Immunohistochemistry showed the large cells to be CD20+ and CD3-. Immunostaining for Epstein-Barr virus (EBV) and cytomegalovirus (CMV) was negative. Special stains including PASD, Grocott, Giemsa, $\mathrm{ZN}$, and Gram stains showed no apparent etiological organisms. The morphological and limited immunohistochemical analysis suggested an abnormal B-cell population, most consistent with post-transplant lymphoproliferative disorder (PTLD). However, the biopsy was small and extensively necrotic which limited the ability to obtain a definitive diagnosis. The remaining FFPE tissue was submitted for clonality analysis of the B-cell population.

The quality of the DNA extracted from the FFPE cecal mass was adequate for clonality analysis as the 400-bp control gene PCR product was successfully amplified. PCR evaluation of B-cell clonality revealed a weak polyclonal result for all BIOMED-2 tubes except for the finding of two distinct oversized bands from the tube for $\mathrm{V}_{\mathrm{K}}-\mathrm{J}_{\mathrm{K}}$ rearrangements (Fig. 4, top panel). Sequencing confirmed the larger band to be a heteroduplex and the smaller band to be a 414-bp homoduplex consisting of $\mathrm{V}_{\mathrm{K}} 2-30$ (192 bp) followed by the 3 '-UTR of $\mathrm{J}_{\mathrm{K}} 4$ through $\mathrm{J}_{\mathrm{K}} 5$ (222 bp) (Fig. 4, bottom panel). The sequence data are consistent with a $\mathrm{VJ}$ rearrangement followed by a deletion of unknown size that occurred at the junction of the two genes. To examine whether the deletion was a germline event, a bone marrow specimen from the same patient, which showed no histological evidence of lymphoid infiltration, was studied for $V_{K}-J_{K}$ rearrangements and the same oversized PCR product was not detectable (data not shown). This result suggests that the deletion was somatic. In addition, there were nine acquired point mutations observed in the remaining $V_{K}$ gene sequence and no recombination signal sequence motifs were identified at or near the joining region of the germline gene segments involved. These findings suggest that the deletion was unlikely to have been introduced during the $\mathrm{V}_{\mathrm{K}}-\mathrm{J}_{\mathrm{K}}$ recombination process, but occurred most likely after the rearrangement of $V_{k} 2-30$ with a $J_{K}$ gene upstream of $J_{K} 5$ when the cell was accumulating somatic mutations [19]. 


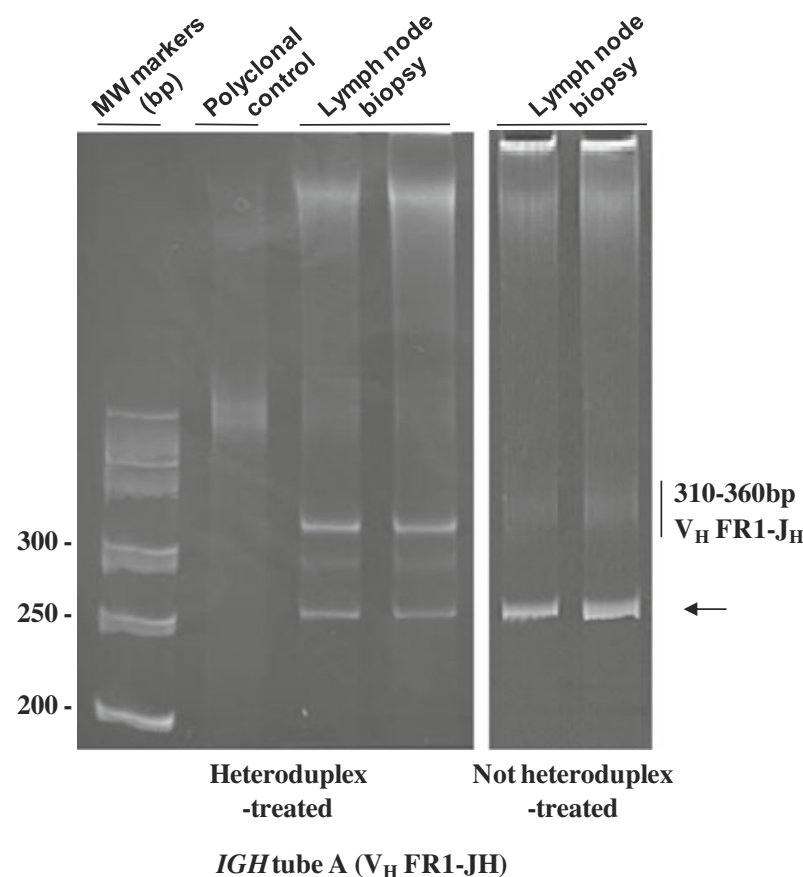

IGH tube A ( $\mathrm{V}_{\mathrm{H}}$ FR1-JH)

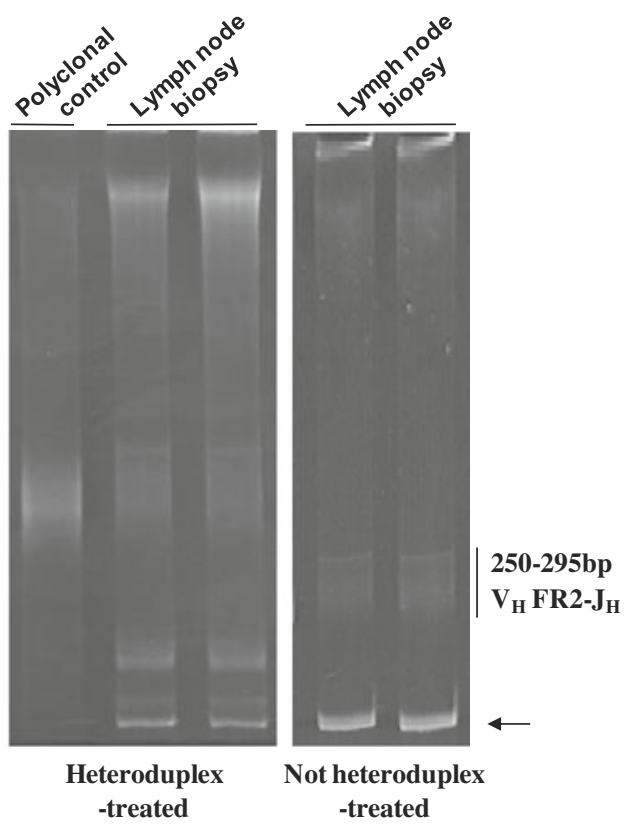

IGH tube B ( $\mathrm{V}_{\mathrm{H}}$ FR2-JH)

\footnotetext{
$-------------V_{\mathrm{H}} 4-59 * 02$ FR2--------------->

Fig. 3 PCR and sequence analysis of the undersized $I G H \mathrm{~V}_{\mathrm{H}}-\mathrm{J}_{\mathrm{H}}$ gene rearrangement from case 2 . The top panels show heteroduplex-PAGE analysis of products from both the $\mathrm{V}_{\mathrm{H}} \mathrm{FR} 1-\mathrm{J}_{\mathrm{H}}$ and $\mathrm{V}_{\mathrm{H}}$ FR2- $\mathrm{J}_{\mathrm{H}}$ PCR tubes using template DNA from the case 2 lymph node biopsy. The patient specimen was analyzed in duplicate. The results reveal an undersized band (arrow) with a polyclonal background. Parallel PAGE analysis of the PCR products without heteroduplex treatment confirmed that the undersized bands from both reactions are homoduplexes. The expected size ranges for each PCR are indicated by

Overall, the oversized $\mathrm{V}_{\mathrm{K}}-\mathrm{J}_{\mathrm{K}}$ PCR products appeared to be amplified from a defective, rearranged $I G K$ gene, thus supporting the morphological and immunohistochemical findings that a clonal B-cell population was present in the biopsy. Two weeks later, a repeat cecal biopsy was taken. The above clonality result was reproduced from the new sample and the histological and immunohistochemical study confirmed the lesion to be a monomorphic EBV-negative B-cell PTLD. vertical lines to right of the gel photographs. The bottom panel shows the sequence of the undersized $\mathrm{V}_{\mathrm{H}} \mathrm{FR} 2-\mathrm{J}_{\mathrm{H}}$ PCR product in bold, with the primer binding sites underlined and labeled with the name of the primer. Analysis of the sequence revealed a 197-bp amplicon that aligned to the germline genes $\mathrm{V}_{\mathrm{H}} 4-59 * 02, \mathrm{D}_{\mathrm{H}} 3-10 * 01$, and $\mathrm{J}_{\mathrm{H}} 4 * 03$. Although the $\mathrm{N}$ region was excessively long (38 bp), an 81-bp deletion of the CDR2 through the 5'-part of FR3 region shortened the rearranged gene to produce the smaller than expected amplicon shown by the PCR in the upper panels

Cases 4-7: Oversized PCR products from rearranged TCRB genes

Peripheral blood and bone marrow aspirate samples from a 40-year-old male were referred for consultation. The patient presented with lymphocytosis (lymphocyte count $77.1 \times 10^{9} /$ L) and generalized lymphadenopathy. Blood film showed pleomorphic small, medium, and large lymphocytes with 

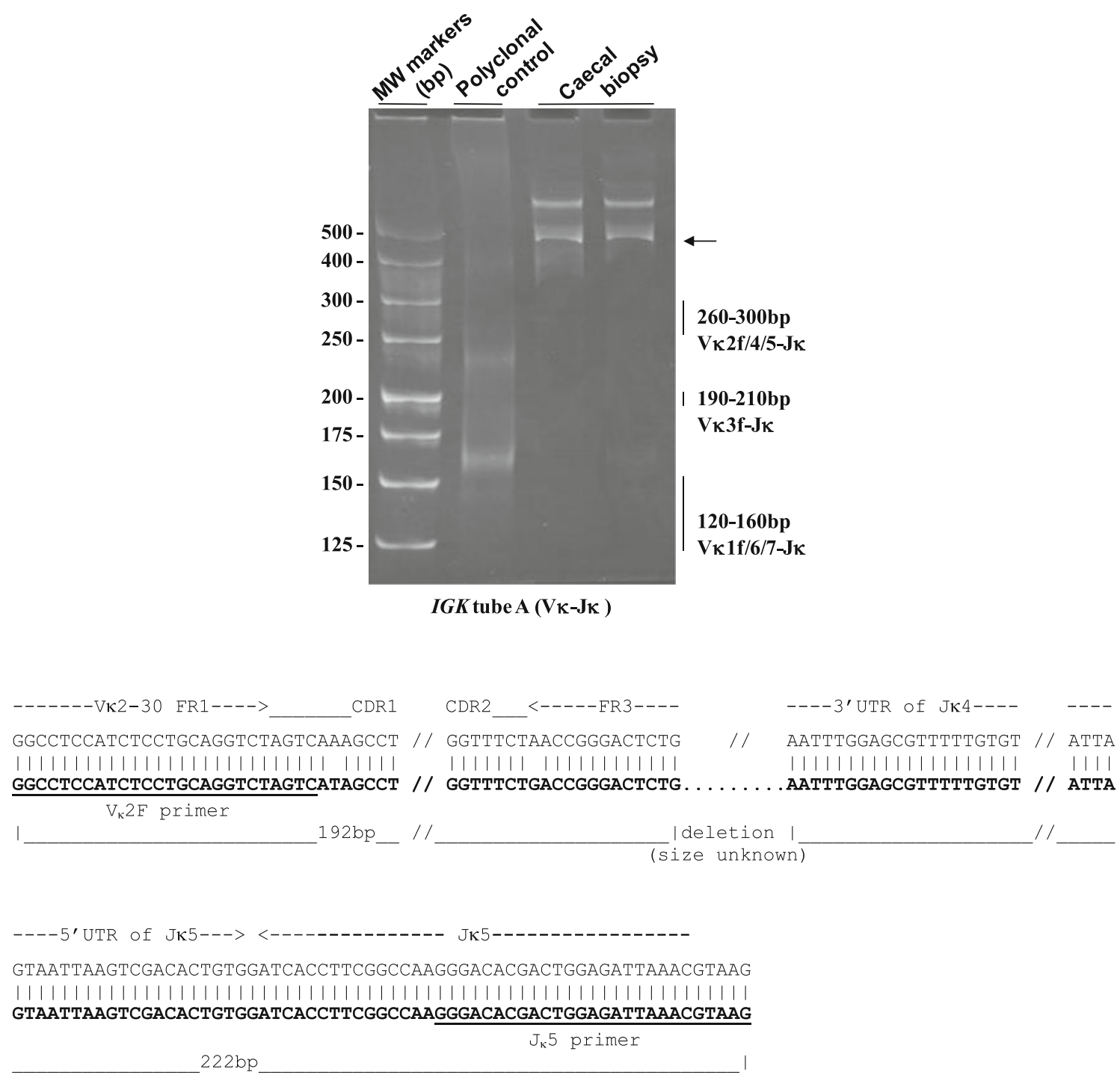

Fig. 4 PCR and sequence analysis of the oversized $I G K \mathrm{~V}_{\mathrm{K}}-\mathrm{J}_{\mathrm{K}}$ gene rearrangement from case 3 . The top panel shows a heteroduplex-PAGE analysis of products from the $\mathrm{V}_{\mathrm{K}}-\mathrm{J}_{\mathrm{K}}$ PCR tube using template DNA from the case 3 cecal mass. The patient specimen was analyzed in duplicate. The results reveal two distinct, oversized bands. The expected size ranges for each PCR are indicated by vertical lines to the right of the gel photograph. The bottom panel shows the sequence of the oversized $I G K \mathrm{~V}_{\mathrm{K}}-\mathrm{J}_{\mathrm{K}}$ PCR product (indicated by the arrow in the

irregular cytoplasm and clear nucleoli. Flow cytometry showed the atypical cells to be mature T-cells of $\mathrm{T}$ suppressor phenotype (CD2+, CD3+, CD5+, CD7+, CD8 +, CD4-, CD25-, CD56-, CD57-, TdT-). The morphology and phenotype favored T-cell prolymphocytic leukemia (T-PLL) and fluorescence in situ hybridization (FISH) and clonality studies were requested to confirm the diagnosis. Interphase FISH showed the atypical T-cells to be positive for the rearrangements at 14q11 (loci of TCRA and TCRD) and deletions at $12 \mathrm{p} 13$ and $11 \mathrm{q} 23$. PCR showed clonal $T C R G$ (tube A) and TCRB (tubes $\mathrm{B}$ and $\mathrm{C}$ ) gene top panel) in bold, with the primer binding sites underlined and labeled with the name of the primer. Portions of the sequence are not shown for clarity, with the missing parts indicated by double slashes (//). Analysis of the sequence revealed that the amplicon was $414 \mathrm{bp}$ and aligned to the germline genes $V_{k} 2-30$ (192 bp) and the $3^{\prime}$-UTR of $J_{K} 4$ through $J_{K} 5$ (222 bp). Much of $V_{k}$ FR3 region is missing, probably due to a deletion of unknown size at the junction (dotted line) following the rearrangement involving one of the upstream $\mathrm{J}_{\mathrm{K}}$ genes

rearrangements. The molecular and cytogenetic results supported the diagnosis of T-PLL.

In addition to the detection of a clonal band from $T C R B$ tube $\mathrm{B}$, an oversized band was amplified from $T C R B$ tube A (Fig. 5, top panel). Sequencing revealed that the oversized PCR band was a 461-bp amplicon that consisted of the rearranged $\mathrm{V}_{\beta} 6.6, \mathrm{D}_{\beta} 2.1$, and $\mathrm{J}_{\beta} 2.1$ genes, and was amplified using the primer specific for $\mathrm{J}_{\beta} 2.2$, which is located $192 \mathrm{bp}$ downstream of $\mathrm{J}_{\beta} 2.1$ (Fig. 5, bottom panel). This oversized amplicon was generated by TCRB tube A because this tube does not contain the PCR primer for the rearranged 

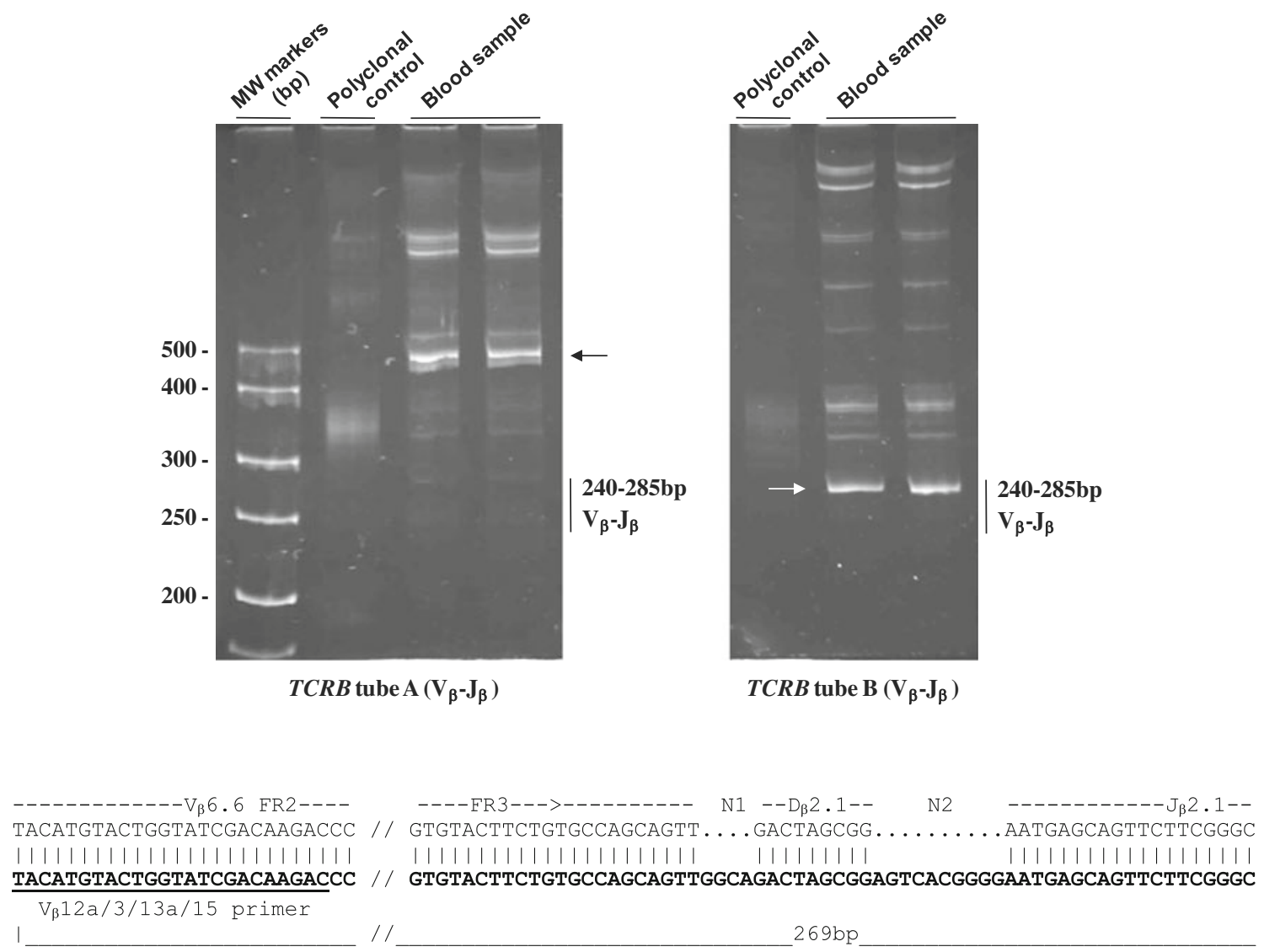

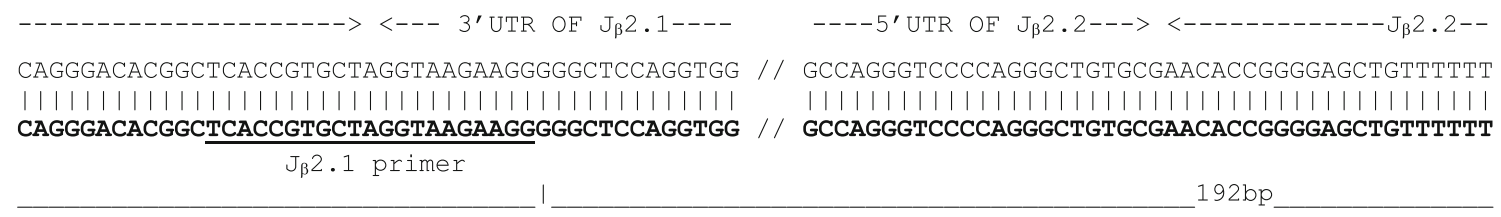

\section{GGAGAAGGCTCTAGGCTGACCGTACTGGGTAAG || || || || || || || ||||||||||||||||||| GGAGAAGGCTCTAGGCTGACCGTACTGGGTAAG \\ $\mathrm{J}_{\beta} 2.2$ primer}

Fig. 5 PCR and sequence analysis of the oversized $T C R \mathrm{~V}_{\beta}-\mathrm{J}_{\beta}$ gene rearrangement from case 4 . The top panel shows a heteroduplex-PAGE analysis of the products from the $\mathrm{V}_{\beta}-\mathrm{J}_{\beta}$ PCR tubes $\mathrm{A}$ and $\mathrm{B}$. The patient specimen (blood sample) was analyzed in duplicate. An oversized band was produced by TCRB tube A (black arrow), and a band within the expected size range by TCRB tube B (white arrow). The expected size ranges for each PCR are indicated by vertical lines to the right of the gel photographs. The bottom panel shows the sequence of the oversized TCRB in bold, with the primer binding sites underlined and labeled with the name of the primer. Portions of the sequence are

$\mathrm{J}_{\beta} 2.1$, but does contain the primer for the immediate downstream $\mathrm{J}_{\beta} 2$ 2.2. Sequencing of the clonal band detected by $T C R B$ tube $\mathrm{B}$, which contained the primer for the rearranged $\mathrm{J}_{\beta} 2.1$, confirmed that it was derived from the same not shown for clarity, with the missing parts indicated by double slashes (//). Sequencing confirmed that the oversized band is a 461bp amplicon of the rearranged $\mathrm{V}_{\beta} 6.6, \mathrm{D}_{\beta} 2.1$, and $\mathrm{J}_{\beta} 2.1$ genes and was amplified using the primer specific for $\mathrm{J}_{\beta} 2.2$, which is located $192 \mathrm{bp}$ downstream of $\mathrm{J}_{\beta} 2.1$. This product was amplified by TCRB tube A because the PCR primer for the upstream rearranged $\mathrm{J}_{\beta} 2-1$ gene was not included in this tube but was present in TCRB tube B. Sequencing of the clonal band detected by TCRB tube B confirmed that it was amplified from the same rearranged gene that was amplified in tube A

rearranged gene that was detected in $T C R B$ tube A (data not shown).

Case 5 concerned a 59-year-old female who presented with splenomegaly. Because of an abnormal lymphocyte 
population that was noted in the blood, blood and bone marrow were sent in for more detailed analysis. Flow cytometric immunophenotyping revealed an aberrant T-cell population ( $230 \%$ of leukocytes). Based on the immunophenotype (CD3+, CD4+, CD8-, CD2+, partly CD5+, CD7+, CD16-, CD56-,CD57-, CD27+, CD45RA +$, CyTCL1+, TCR $\alpha \beta+$, TCRV $\beta-)$, a T-cell leukemia was suspected, possibly of T-PLL type. Clonality analysis revealed clonal TCRB and TCRG products, supporting the immunophenotypic suspicion of a mature T-cell malignancy. Notably, upon TCRB analysis, an oversized $377 \mathrm{bp}$ product was identified in tube A (Fig. 6a). Given the small intergenic distances in the TCRB $\mathrm{J}$ regions, a logical explanation for such a large amplicon would be extended amplification of a true rearrangement from a downstream $\mathrm{J}$ gene. Indeed, a clonal 259-bp product was seen in tube B

A

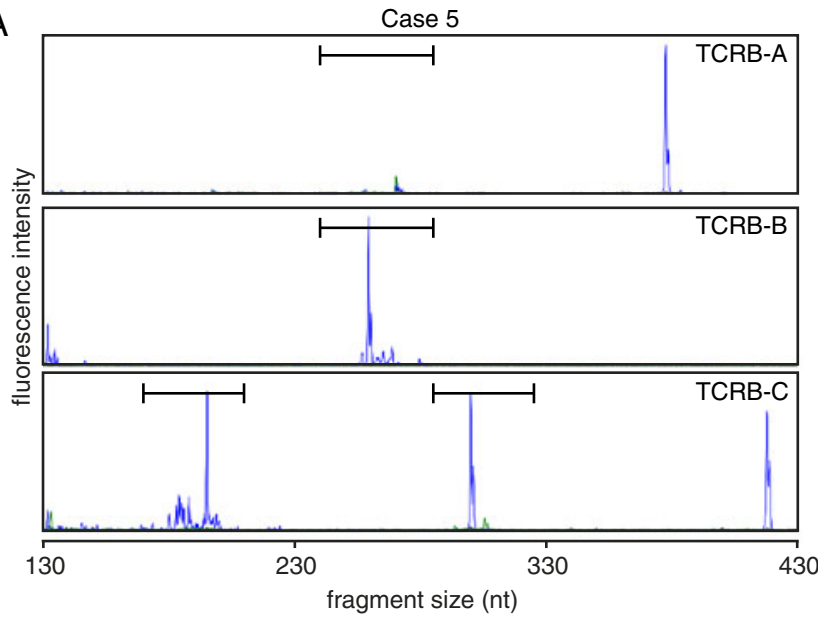

C

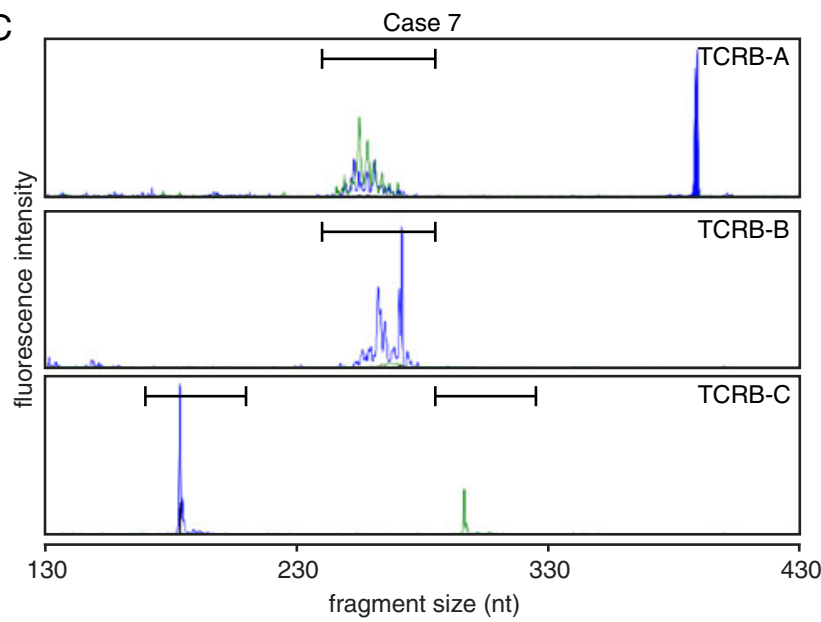

Fig. 6 GeneScan analysis of oversized TCRB rearrangement products using BIOMED-2 multiplex tubes $(\mathrm{V} \beta-\mathrm{J} \beta$ tube $\mathrm{A}$, upper electropherograph panel; $\mathrm{V} \beta-\mathrm{J} \beta$ tube $\mathrm{B}$, middle panel; $\mathrm{D} \beta-\mathrm{JB}$ tube $\mathrm{C}$, lower panel) for each case. For each panel, horizontal lines indicate the expected size range based on the positions of the primers and known patterns of trimming and $\mathrm{N}$-addition during recombination. a Case 5 showing oversized products in the upper and lower panels,
(Fig. 6a). The size difference of $\sim 120 \mathrm{bp}$ suggests that the rearrangement that is seen in tube $B$ concerns a $V \beta-J \beta 2.5$ rearrangement that is amplified by a primer specific for the downstream $\mathrm{J} \beta 2.6$ gene, which is present in tube A. Likewise, the $300-b p D \beta-J \beta$ rearrangement was also amplified as an extended product of $417 \mathrm{bp}$, most likely reflecting a $\mathrm{D} \beta-\mathrm{J} \beta 2.4$ amplicon that was additionally amplified from the downstream $\mathrm{J} \beta 2.5$ gene (Fig. 6a).

Case 6 was a 40-year-old male who was referred because of a suspicious T-cell population in the blood in the context of skin lesions that were present for several months. More detailed immunophenotyping of the blood was performed, showing an aberrant T-cell population $(\mathrm{CD} 3+, \mathrm{CD} 4-, \mathrm{CD} 8$ ,$+ \mathrm{CD} 2+, \mathrm{CD} 5-, \mathrm{CD} 7+, \mathrm{CD} 27-, \mathrm{CD} 45 \mathrm{RO}+, \mathrm{TCR} \alpha \beta+$, TCRV $\beta-)$ with a relative size of $33 \%$ of the leukocytes. Upon molecular analysis, clonal TCRB and TCRG products

B

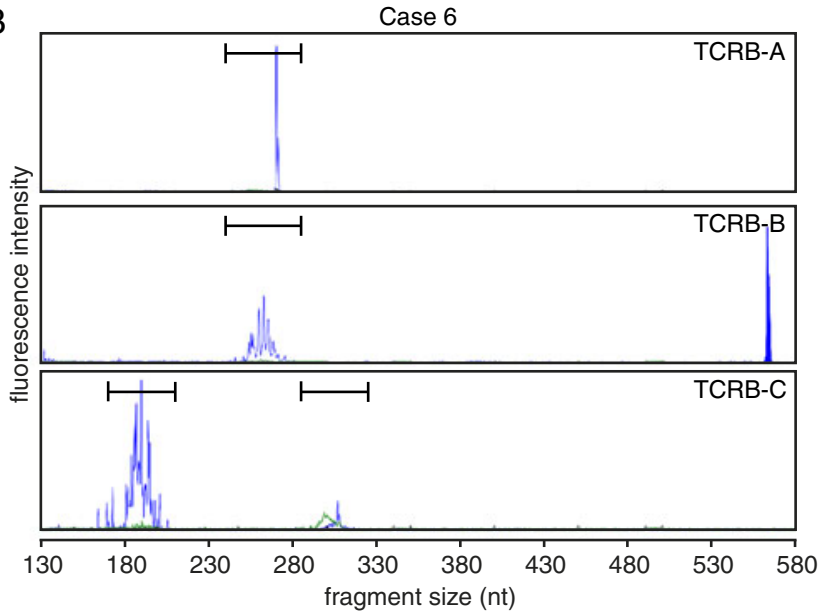

representing extended amplicons from the true rearrangement products in the middle and lower panels, respectively. b Case 6 showing an oversized product in the middle panel and the true rearrangement product in the upper panel. c Case 7 showing an oversized product in the upper panel and the true rearrangement product in the middle panel. See text for more details 
were seen. TCRB multiplex tube A showed a clonal 270-bp product, whereas in tube $\mathrm{B}$, a polyclonal pattern was observed in addition to an oversized 562-bp product (Fig. 6b). This combination of products is compatible with a correctly sized $\mathrm{V} \beta-\mathrm{J} \beta 2.2$ product (tube $\mathrm{A}$ ) that was amplified with a specific primer for the downstream $J \beta 2.3$ gene giving rise to an oversized PCR product (tube B). This was confirmed by sequence analysis (data not shown), revealing that the oversized band consisted of rearranged $V_{\beta} 4-2, D_{\beta} 2$, and $J_{\beta} 2.2$ genes, and was amplified using the primer specific for $\mathrm{J}_{\beta} 2.3$, which is located $285 \mathrm{bp}$ downstream of $\mathrm{J}_{\beta} 2.2$.

Case 7 was a 45 -year-old woman with a T-NHL. Bone marrow was sent in for staging. Upon flow cytometric analysis, a small T-cell population (3\% of leukocytes) was noted with an aberrant phenotype: CD3dim, CD4+,CD8-, $\mathrm{CD} 2+, \mathrm{CD} 5++, \mathrm{CD} 7-, \mathrm{CD} 25+, \mathrm{CD} 27+, \mathrm{CD} 45 \mathrm{RO}+$, $\mathrm{TCR} \alpha \beta+, \mathrm{V} \beta 2+$. Molecular clonality testing confirmed the clonal character of the aberrant T-cell population in the bone marrow. In TCRB tube $\mathrm{B}$, a polyclonal profile was found in combination with a clonal peak of $272 \mathrm{bp}$ (Fig. 6c). The oversized 389-bp product in tube A that was seen next to a polyclonal profile is compatible with amplification of the tube $B V \beta-J \beta$ rearrangement from a downstream $J \beta$ gene (Fig. 6c). Based on the size difference between the two products and the division of the $\mathrm{J} \beta 2$ primers over tubes $\mathrm{A}$ and $B$, these results were interpreted as a $V \beta-J \beta 2.5$ rearrangement that is amplified with a $\mathrm{J} \beta 2.5$ primer (tube $\mathrm{B}$ ) and with a $\mathrm{J} \beta 2.6$ primer (tube $\mathrm{A}$ ).

\section{Discussion}

The finding of too large or small amplicons after evaluation of clonality of a lymphoproliferation using PCR of the antigen receptor genes is an uncommon, but not rare event. When a DNA fragment is outside the acceptable size range, it is not usually considered to be evidence for clonality. In the cases shown here, and in several previously published cases, a DNA fragment far outside this size range has been shown to provide good evidence for monoclonality, but only after nucleotide sequence analysis. In the cases shown here, analysis of the nucleotide sequence revealed features consistent with an IGH, IGK, or TCRB gene rearrangement. In particular, the sequences contained evidence for the presence of a $\mathrm{V}$ gene joined to a $\mathrm{J}$ gene. In addition, the sequences give clues to why the size of the amplicon was out of range.

There are several reasons why an amplicon representing a genuine gene rearrangement would fall outside the expected size range. The expected size ranges defined in the BIOMED-2 protocols encompass approximately $95 \%$ of the center of the Gaussian distribution of amplicon sizes [20]. Thus, approximately $5 \%$ of the rearrangements will be a bit larger or smaller than the expected size range. These amplicons are acceptable proof of clonality. It is not necessary in a heteroduplex analysis on a polyacrylamide gel to precisely define the acceptable size range. Similarly, when the separation is done by capillary electrophoresis, an amplicon that is only out of range by up to $10 \mathrm{bp}$ should still be considered an adequate evidence for clonality.

Amplicons that are vastly different in size are more problematic as several such DNA fragments have been seen that are not consistent with a clonal lymphoproliferation [3]. These may be due to amplification products that are generated by nonspecific annealing of primers to sequences that are not the intended target in the antigen receptor genes, or amplification of a germline fragment in an antigen receptor gene. An example of the latter is the 211-bp amplicon generated from $\mathrm{D}_{\mathrm{H}} 7-27 / \mathrm{J}_{\mathrm{H}}$ by $I G H$ tube E PCR as reported by van Dongen et al. [3]. Most of the time, these nonspecific PCR products will not pose an interpretive problem as the signal will also be noted in a normal or non-germline control. Such nonspecific bands are summarized in Table 25 of van Dongen et al. [3]. It is possible that novel nonspecific amplicons might be found after antigen receptor PCR due to sequence variants in the germline, but this event has not been reported to our knowledge. Thus, when an aberrantly sized amplicon is encountered that is not seen in the normal control, it may represent a clonal rearrangement as described in several cases in this article and elsewhere, or it may be an artifact that does not indicate clonality $[3,16,21]$.

Amplicons that are out of range by more than approximately $10 \mathrm{bp}$, as in the cases reported here, require additional explanation before they can be interpreted as molecular evidence of clonality. Amplicons that are smaller than the expected size range may be due to a deletion of DNA as in case 2 and reported previously for the $I G H$ gene $[16,17]$. Larger than expected amplicons are more common and may be due to somatic mutation, germline polymorphisms, or deletion of a $\mathbf{J}$ gene with successful priming on the next downstream $\mathrm{J}$ gene. This type of event was seen for the $I G H$ and $I G K$ genes in cases 1 and 3, respectively. In case 1 , the $\mathrm{J}_{\mathrm{H}}$ gene primer differed from the rearranged $\mathrm{J}_{\mathrm{H}} 4$ gene by three nucleotides, two of which were likely due to somatic hypermutation, allowing a product derived from priming on the downstream $\mathrm{J}_{\mathrm{H}} 5$ gene. In case 3 , the downstream $\mathrm{J}_{\mathrm{K}}$ primer hybridized to $\mathrm{J}_{\mathrm{K}} 5$ to generate the amplicon, but the presence of sequence from the $\mathrm{J}_{\mathrm{K}} 4-\mathrm{J}_{\mathrm{K}} 5$ intergenic region suggests that an upstream $J_{K}$ gene was actually used in the rearrangement and then deleted. Similar events are possible for the $\mathrm{V}$ genes if the next upstream $\mathrm{V}$ gene is close enough to generate an amplicon. Deletions and insertions in rearranged IG genes are quite common in normal germinal center and post-germinal center B-cells and the malignancies derived from these cells [19, 22-25]. They appear to be a consequence of the process of somatic hypermutation [19]. 
Downstream priming is especially feasible in the $I G H, I G K$, and TCRB loci, in which the intergenic distances in the $\mathrm{J}$ regions are rather small (Fig. 7). Intergenic distances in the $T C R G$ locus are too large for efficient amplification from downstream J genes.

A larger amplicon from the TCRB gene is seen in cases 4-7. However, unlike the IG gene cases in the previous paragraph, the cause of these oversized amplicons is due to the strategy worked out by the BIOMED-2 consortium and not to a genetic alteration at the locus (Figs. 5, 6, and 7). The BIOMED-2 PCR assay for $\mathrm{V} \beta-\mathrm{J} \beta$ rearrangements was designed to divide seven $\mathrm{J} \beta 2$ primers into two PCR tubes, both of which contain the same set of $\mathrm{V} \beta$ primers. Therefore, the same clonal V $\beta-\mathrm{J} \beta 2$ rearrangement can be amplified in both tubes, with one tube giving rise to a product of correct size and the other tube generating an oversized product using the primer specific to the $\mathrm{J} \beta$ segment immediately downstream to the rearranged $\mathrm{J} \beta$ gene $[3,21]$. In
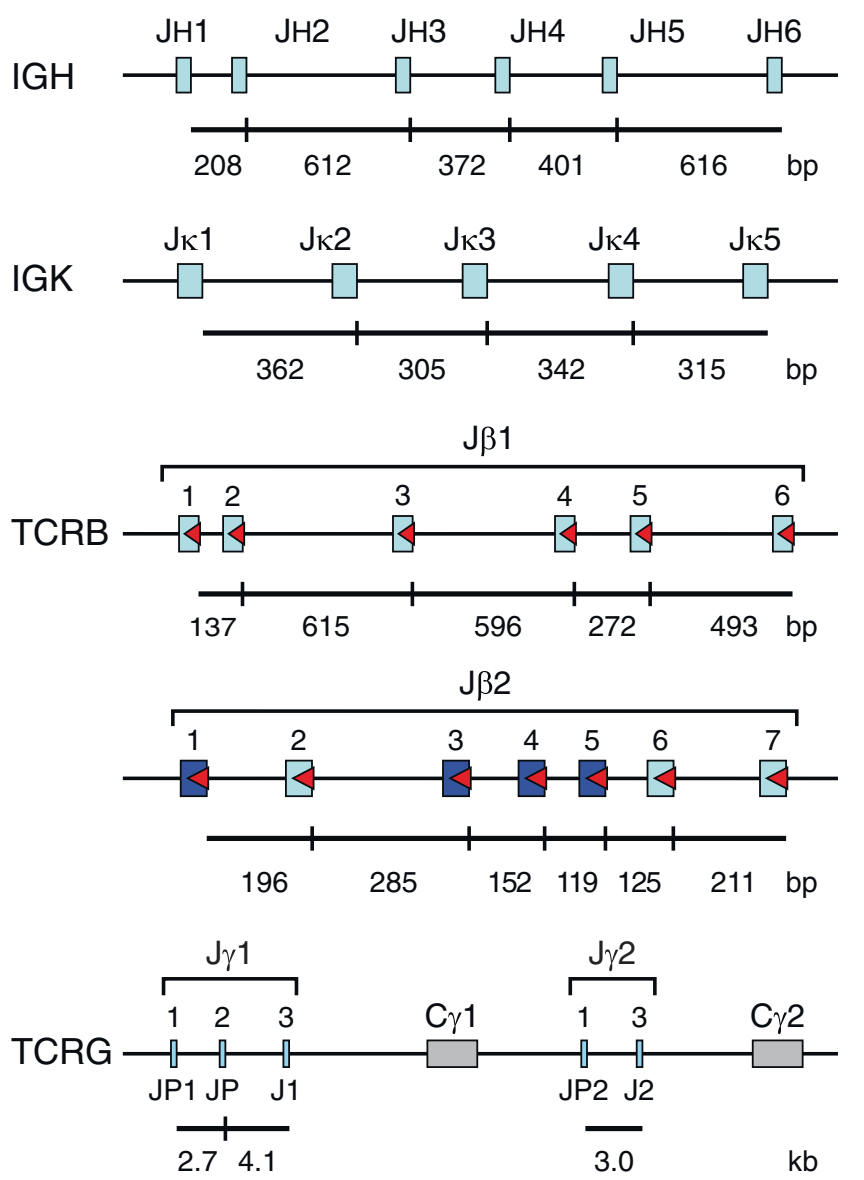

Fig. 7 Intergenic distances for the $\mathrm{J}$ regions of the $I G H, I G K, T C R B$, and $T C R G$ loci. The numbers represent the distances in nucleotides. The TCRB primers for the J genes shown in light blue are in BIOMED2 multiplex tube $\mathrm{A}$, whereas primers for the $\mathrm{J}$ genes shown in dark blue are in BIOMED-2 multiplex tube B. Note that the distances for all loci, except for $T C R G$, are small, enabling efficient PCR amplification from a downstream $\mathrm{J}$ gene addition, the small intergenic distances in both the $\mathrm{J} \beta 1$ and $\mathrm{J} \beta 2$ regions make the amplification of two differently sized PCR products from one TCRB tube possible because of efficient primer annealing to both the rearranged and the next downstream $\mathrm{J} \beta$ gene. For two cases presented here (cases 4 and 6), and a case previously published [21], sequence analysis of the oversized amplicons confirmed that they were due to this aspect of assay design.

Is it always necessary to sequence an over or undersized amplicon from PCR of the antigen receptor genes? Considering that the BIOMED-2 protocol consists of PCRs for several targets for each lineage, and the use of multiple targets is recommended for routine clonality analysis, if another tube for the same target gene or another antigen receptor target gene gives a convincing monoclonal result within the expected size range, then sequence analysis of the aberrantly sized amplicon is not strictly necessary. For example, if $I G H$ PCR gives an undersized amplicon, but $I G K$ PCR gives an abundant amplicon in the proper size range as shown in case 2 , then the results are consistent with a monoclonal lymphoproliferation, and sequencing of the undersized amplicon is not needed to prove this point. Similarly for the TCRB gene, if PCR with tube A produces a single strong band in the proper size range, then a finding of an oversized amplicon in tube B (as seen in case 6) does not provide evidence contrary to a conclusion of a monoclonal lymphoproliferation, and sequencing of the oversized amplicon is not necessary.

Sequence analysis of the amplicon from antigen receptor gene PCR is not difficult. If the product is only a single amplicon with little or no polyclonal signal, the PCR product can be sequenced directly after treatment with ExoSap to enzymatically eliminate the primers and dNTPs. If more than one amplicon is seen or if there is abundant polyclonal signal, the PCR product template should be gel-purified. The initial sequencing reaction should use the J gene PCR primers described in the initial BIOMED-2 publication [3] because there are fewer such primers. If there is more than one $\mathrm{J}$ gene primer in the PCR mix that gave the amplicon with an aberrant size, they can be combined in the sequencing mix. After the initial sequence is obtained, it is likely that there will be enough information to get a clear interpretation concerning the nature of the event that led to the aberrant size of the amplicon. If not, the sequence can be completed using an upstream primer determined from the initial round of sequencing.

In summary, we present several cases in which PCR of an antigen receptor gene generated an amplicon that was far outside the acceptable size range for a result that supports an interpretation of a population of monoclonal lymphocytes. However, sequence analysis showed that the amplicon structure was consistent with clonality. Thus, when an undersized or oversized PCR product is the only molecular 
evidence for clonality, this interpretation should be confirmed by nucleotide sequence analysis prior to reporting.

Acknowledgments The authors would like to thank Sandra de Bruin-Versteeg and Marieke Comans-Bitter for preparing the figures.

Conflict of interest The authors declare that they have no conflict of interest.

\section{References}

1. Tonegawa S (1983) Somatic generation of antibody diversity. Nature 302:575-581

2. Davis MM, Bjorkman PJ (1988) T-cell antigen receptor genes and T-cell recognition. Nature 334:395-402

3. van Dongen JJ, Langerak AW, Bruggemann M et al (2003) Design and standardization of PCR primers and protocols for detection of clonal immunoglobulin and T-cell receptor gene recombinations in suspect lymphoproliferations: report of the BIOMED-2 Concerted Action BMH4-CT98-3936. Leukemia 17:2257-2317

4. Sandberg Y, Heule F, Lam K, Lugtenburg PJ, Wolvers-Tettero ILM, van Dongen JJM, Langerak AW (2003) Molecular immunoglobulin/T-cell receptor clonality analysis in cutaneous lymphoproliferations. Experience with the BIOMED-2 standardized polymerase chain reaction protocol. Haematologica 88:659-670

5. McClure RF, Kaur P, Pagel E, Ouillette PD, Holtegaard CE, Treptow CL, Kurtin PJ (2006) Validation of immunoglobulin gene rearrangement detection by PCR using commercially available BIOMED-2 primers. Leukemia 20:176-179

6. Brüggemann M, White H, Gaulard P et al (2007) Powerful strategy for polymerase chain reaction-based clonality assessment in T-cell malignancies Report of the BIOMED-2 Concerted Action BHM4 CT98-3936. Leukemia 21:215-221

7. Evans P, Pott C, Groenen PJ et al (2007) Significantly improved PCR-based clonality testing in B-cell malignancies by use of multiple immunoglobulin gene targets. Report of the BIOMED-2 Concerted Action BHM4-CT98-3936. Leukemia 21:207-214

8. Halldórsdóttir AM, Zehnbauer BA, Burack WR (2007) Application of BIOMED-2 clonality assays to formalin-fixed paraffin embedded follicular lymphoma specimens: superior performance of the IGK assays compared to IGH for suboptimal specimens. Leuk Lymphoma 48:1338-1343

9. Langerak AW, Molina TJ, Lavender FL et al (2007) Polymerase chain reaction-based clonality testing in tissue samples with reactive lymphoproliferations: usefulness and pitfalls. A report of the BIOMED-2 Concerted Action BMH4-CT98-3936. Leukemia 21:222-229

10. Liu H, Bench AJ, Bacon CM, Payne K, Huang Y, Scott MA, Erber WN, Grant JW, Du MQ (2007) A practical strategy for the routine use of BIOMED-2 PCR assays for detection of B- and T-cell clonality in diagnostic haematopathology. Br J Haematol 138:31-43

11. Chute DJ, Cousar JB, Mahadevan MS, Siegrist KA, Silverman LM, Stoler MH (2008) Detection of immunoglobulin heavy chain gene rearrangements in classic Hodgkin lymphoma using commercially available BIOMED-2 primers. Diagn Mol Pathol 17:65-72

12. Hebeda KM, Van Altena MC, Rombout P, Van Krieken JH, Groenen PJ (2009) PCR clonality detection in Hodgkin lymphoma. J Hematopathol 2:34-41

13. Burack WR, Laughlin TS, Friedberg JW, Spence JM, Rothberg PG (2010) PCR assays detect B-lymphocyte clonality in formalinfixed, paraffin-embedded specimens of classical Hodgkin lymphoma without microdissection. Am J Clin Pathol 134:104-111

14. Zhang B, Beck AH, Taube JM et al (2010) Combined use of PCRbased TCRG and TCRB clonality tests on paraffin-embedded skin tissue in the differential diagnosis of mycosis fungoides and inflammatory dermatoses. J Mol Diagn 12:320-327

15. Payne K, Wright P, Grant JW, Huang Y, Hamoudi R, Bacon CM, Du MQ, Liu H (2011) BIOMED-2 PCR assays for IGK gene rearrangements are essential for B-cell clonality analysis in follicular lymphoma. Br J Haematol 155:84-92

16. Vargas RL, Felgar RE, Rothberg PG (2008) Detection of clonality in lymphoproliferations using PCR of the antigen receptor genes: does size matter? Leuk Res 32:335-338

17. Liao YL, Chang ST, Kuo SY, Lin SH, Chen CK, Chang KM, Chuang SS (2010) Angioimmunoblastic T-cell lymphoma of cytotoxic T-cell phenotype containing a large B-cell proliferation with an undersized B-cell clonal product. Appl Immunohistochem Mol Morphol 18:185-189

18. Altschul SF, Madden TL, Schäffer AA, Zhang J, Zhang Z, Miller W, Lipman DJ (1997) Gapped BLAST and PSI-BLAST: a new generation of protein database search programs. Nucleic Acid Res 25:3389-3402

19. Goossens T, Klein U, Küppers R (1998) Frequent occurrence of deletions and duplications during somatic hypermutation: implications for oncogene translocations and heavy chain disease. Proc Natl Acad Sci U S A 95:2463-2468

20. Langerak AW, Groenen PJ, van Krieken JH, van Dongen JJ (2007) Immunoglobulin/T-cell receptor clonality diagnostics. Expert Opin Med Diagn 1:451-461

21. Langerak AW (2008) Undersized, oversized? It is not one-size-fitsall in lymphoid clonality detection. Leuk Res 32:203-204

22. Küppers R, Rajewsky K, Zhao M, Simons G, Laumann R, Fischer R, Hansmann M-L (1994) Hodgkin disease: Hodgkin and ReedSternberg cells picked from histological sections show clonal immunoglobulin gene rearrangements and appear to be derived from B cells at various stages of development. Proc Natl Acad Sci U S A 91:10962-10966

23. Klein U, Klein G, Ehlin-Henriksson B, Rajewsky K, Küppers R (1995) Burkitt's lymphoma is a malignancy of mature B cells expressing somatically mutated $\mathrm{V}$ region genes. Mol Med 1:495505

24. Kanzler H, Küppers R, Hansmann ML, Rajewsky K (1996) Hodgkin and Reed-Sternberg cells in Hodgkin's disease represent the outgrowth of a dominant tumor clone derived from (crippled) germinal center B cells. J Exp Med 184:1495-1505

25. Küppers R, Rajewsky K, Hansmann ML (1997) Diffuse large cell lymphomas are derived from mature $\mathrm{B}$ cells carrying $\mathrm{V}$ region genes with a high load of somatic mutation and evidence of selection for antibody expression. Eur J Immunol 27:1398-1405 